\title{
Growth and Characterization of L-glutamic Acid Hydro Chloro Bromide, A New Nonlinear Optical Material
}

\author{
S. Kumararaman ${ }^{a}$, K. Kirubavathi ${ }^{b}$, K. Selvaraju ${ }^{c, *}$ \\ ${ }^{a}$ Department of Physics, Nehru Memorial College, Puthanampatti-621 007, India \\ ${ }^{b}$ Department of Physics, Govt. Arts College for Women, Kumbakonam-612 001, India \\ ${ }^{c}$ Department of Physics, Govt. Arts College, Ariyalur-621 713, India \\ *Corresponding Author: selsphy@yahoo.com, selvaraju17@rediffmail.com
}

\begin{abstract}
The influence of mixed acids in the growth and characteristic properties of a nonlinear optical material L-glutamic acid hydro chloro bromide abbreviated as LGAHCB was examined. Single crystal X-ray diffraction analysis was used to calculate the lattice parameters of the crystals. Fourier transform infrared spectroscopies were performed to study the molecular vibrations of the grown crystal. The optical transmission spectrum shows very low absorption in the entire visible region. The powder second harmonic generation efficiency of LGAHCB is 1.5 times efficient as potassium dihydrogen phosphate (KDP).
\end{abstract}

Key words: Growth from solution; Single crystal X-ray diffraction; Infrared spectrum; Nonlinear optical materials

\section{INTRODUCTION}

Nonlinear optics is concerned with the interaction of electromagnetic fields with various media to produce new electromagnetic fields altered in phase, frequency and amplitude from the incident fields. Second harmonic generation (SHG) is an example of second order nonlinear optical (NLO) process [1,2]. Nonlinear optical materials are capable of producing higher values of the original frequency and hence this phenomenon can find application in optical modulation, fiber optic communication and opto-electronics [3]. In the last decades, many researchers have tried to find varieties of new NLO materials for laser applications [4,5] . 
Complexes of organic material with inorganic acids and salts are promising materials for optical second harmonic generations they tend to combine the features of organic with that of inorganic materials. In the recent years, amino acid family crystals are of interest due to their attractive nonlinear optical properties [6,7]. The salts of amino acids like L-arginine [8], L-histidine [9], L-threonine [10], L-alanine [11], L-valine [12], and L-cystine [13] are some of the examples which proved their application in the field of NLO.

In the present investigation, an attempt has been made to grow L-glutamic acid hydro chloro bromide (LGAHCB) by solvent evaporation method at room temperature. Highly transparent optical quality crystals were grown. The grown crystals have been subjected to structural, spectroscopic, nonlinear optical property and mechanical characterization studies.

\section{EXPERIMENTAL}

\subsection{Synthesis}

The starting material was synthesized by taking L-glutamic acid hydro chloride and L-glutamic acid hydro bromide (Loba Chemie-AR grade) in a 1:1 stoichiometric ratio. The required amount of starting materials for the synthesis of L-glutamic acid hydro chloro bromide (LGAHCB) salt was calculated according to the reaction

\section{$\mathrm{C}_{5} \mathrm{H}_{10} \mathrm{NO}_{4} \mathrm{Cl}+\mathrm{C}_{5} \mathrm{H}_{10} \mathrm{NO}_{4} \mathrm{Br} \longrightarrow \mathrm{C}_{10} \mathrm{H}_{20} \mathrm{~N}_{2} \mathrm{O}_{8} \mathrm{Cl} \mathrm{Br}$}

The calculated amount of L-glutamic acid hydro chloride was first dissolved in deionized water. L-glutamic acid hydro bromide was then added to the solution slowly by stirring. The prepared solution was allowed to dry at room temperature and the salts were obtained by slow evaporation technique. The purity of the synthesized salt was further improved by successive recrystallization process.

\subsection{Solubility}

The solubility of LGAHCB in deionized water was determined as a function of temperature in the temperature range of $30-45^{\circ} \mathrm{C}$. The beaker containing the solution was maintained at a constant temperature and continuously stirred. The amount of LGAHCB required to saturate at this temperature was estimated and this process repeated for various temperatures. On reaching saturation, the equilibrium concentration of the solute was determined by gravimetric method. The variation of solubility with temperature is shown in Fig.1. 


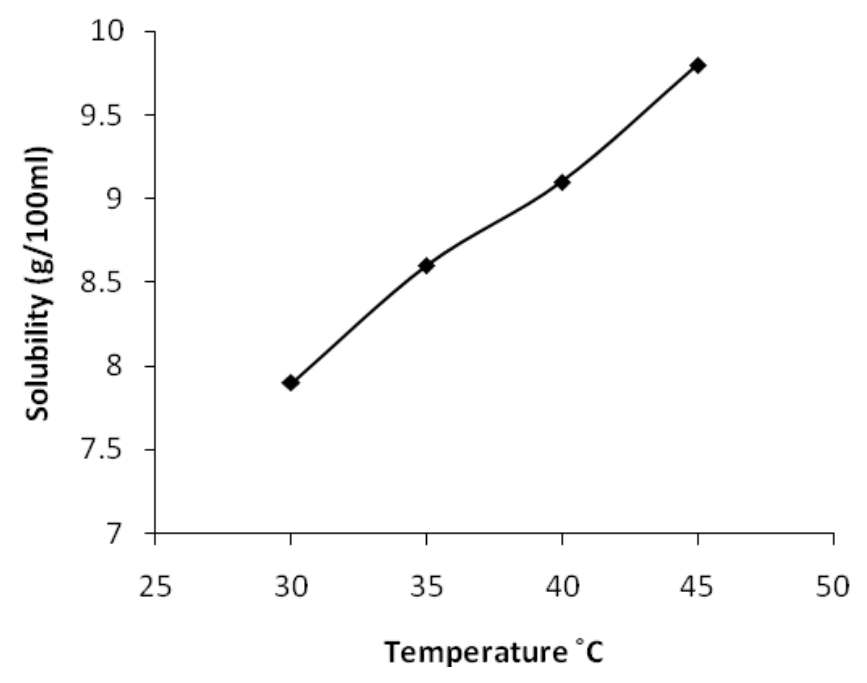

Fig. 1. Solubility of LGAHCB

\subsection{Crystal growth}

The saturated solution of LGAHCB was prepared at room temperature from the recrystallized salt. The solution was then filtered twice to remove the suspended impurities and allowed to crystalline by the slow evaporation technique at room temperature. A good optical transparent crystal of size $18 \times 10 \times 6 \mathrm{~mm}^{3}$ harvested in a growth period of 30 days is shown in Fig.2.

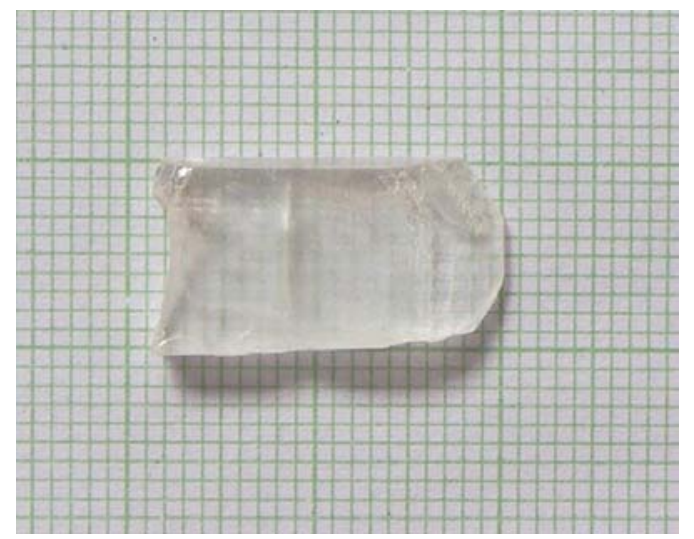

Fig. 2. As grown LGAHCB single crystal

\section{CHARACTERIZATION}

The single crystal X-ray diffraction analysis of LGAHCB crystal was carried out using ENRAF NONIUS CAD4 X-ray diffractometer and its lattice parameters were determined. Fourier transform infrared spectrum was recorded by the $\mathrm{KBr}$ pellet technique using a BRUKER 66V 
FTIR spectrometer to confirm the vibrational structure of the crystalline compound with scanning range of wavenumber $400-4000 \mathrm{~cm}^{-1}$. UV-Visible spectrum was recorded in the range of 200-1400nm using VARIAN CARY 5E spectrometer. The NLO property of LGAHCB was tested by Kurtz powder SHG test using an Nd:YAG laser (1064nm).

\section{RESULTS AND DISCUSSIONS}

\subsection{Single Crystal X-ray Diffraction}

The grown crystals were analyzed by single crystal X-ray diffraction method using ENRAF NONIUS CAD4 diffractometer. The structure was refined by full matrix least squares method using SHELX program. It is observed that the LGAHCB single crystal belongs to orthorhombic crystal system and unit cell dimensions $a=11.121 \mathrm{~A}^{\circ}, \mathrm{b}=14.030 \mathrm{~A}^{\circ}, \mathrm{c}=5.343 \mathrm{~A}^{\circ}$. The observed data are in very good agreement with previous determination [14].

\subsection{FTIR Analysis}

The FTIR spectrum of LGAHCB crystal was recorded in the $\mathrm{KBr}$ pellet technique in the frequency region 400-4000 $\mathrm{cm}^{-1}$ using BRUKER 66V FTIR spectrometer. The recorded FTIR spectrum of LGAHCB crystal is shown in Fig.3. The comparison of vibration of L-glutamic acid and LGAHCB is shown in Table 1.

The broad and strong absorption band between 2100 and $3400 \mathrm{~cm}^{-1}$ are assigned to the hydrogen bonded $\mathrm{NH}_{3}{ }^{+}$stretching modes. The intense sharp peaks at $2903 \mathrm{~cm}^{-1}$ are due to the $\mathrm{CH}$ stretching modes of vibration. The $\mathrm{C}=\mathrm{O}$ stretching modes of vibration is observed at 1683 and $1724 \mathrm{~cm}^{-1}$. The intense sharp peaks at $1503 \mathrm{~cm}^{-1}$ are due to $\mathrm{NH}_{3}{ }^{+}$symmetric deformation. The less intense sharp peak at $1417 \mathrm{~cm}^{-1}$ is due to the $\mathrm{CH}_{2}$ bending modes of vibration. The $\mathrm{C}-\mathrm{C}-\mathrm{H}$ bending modes of vibration are observed at $1370 \mathrm{~cm}^{-1}$. There are less intense resolved bands at $1268 \mathrm{~cm}^{-}$ ${ }^{1}$ are attributed to $\mathrm{CH}_{2}$ twisting. The $\mathrm{C}-\mathrm{O}$ stretching modes of vibrations and $\mathrm{O}-\mathrm{H}$ in-plane bending modes of vibration is observed at $1205 \mathrm{~cm}^{-1}$. The less intense peak observed at 1075 $\mathrm{cm}^{-1}$ is due to the $\mathrm{NH}_{2}$ rocking. The $\mathrm{C}-\mathrm{C}$ stretching modes of vibration and $\mathrm{O}-\mathrm{H}$ out of-plane bending modes of vibrations are observed at $852 \mathrm{~cm}^{-1}$. The band observed at $628 \mathrm{~cm}^{-1}$ is assigned to $\mathrm{C}=\mathrm{O}$ in plane bending of $\mathrm{COOH}$ [15-17]. The $\mathrm{NH}$ torsion and rocking of $\mathrm{COO}^{-}$is assigned to the band observed at 531 and $488 \mathrm{~cm}^{-1}$. This observation confirms the protonation of L-glutamic acid by hydro chloro bromic acid. 


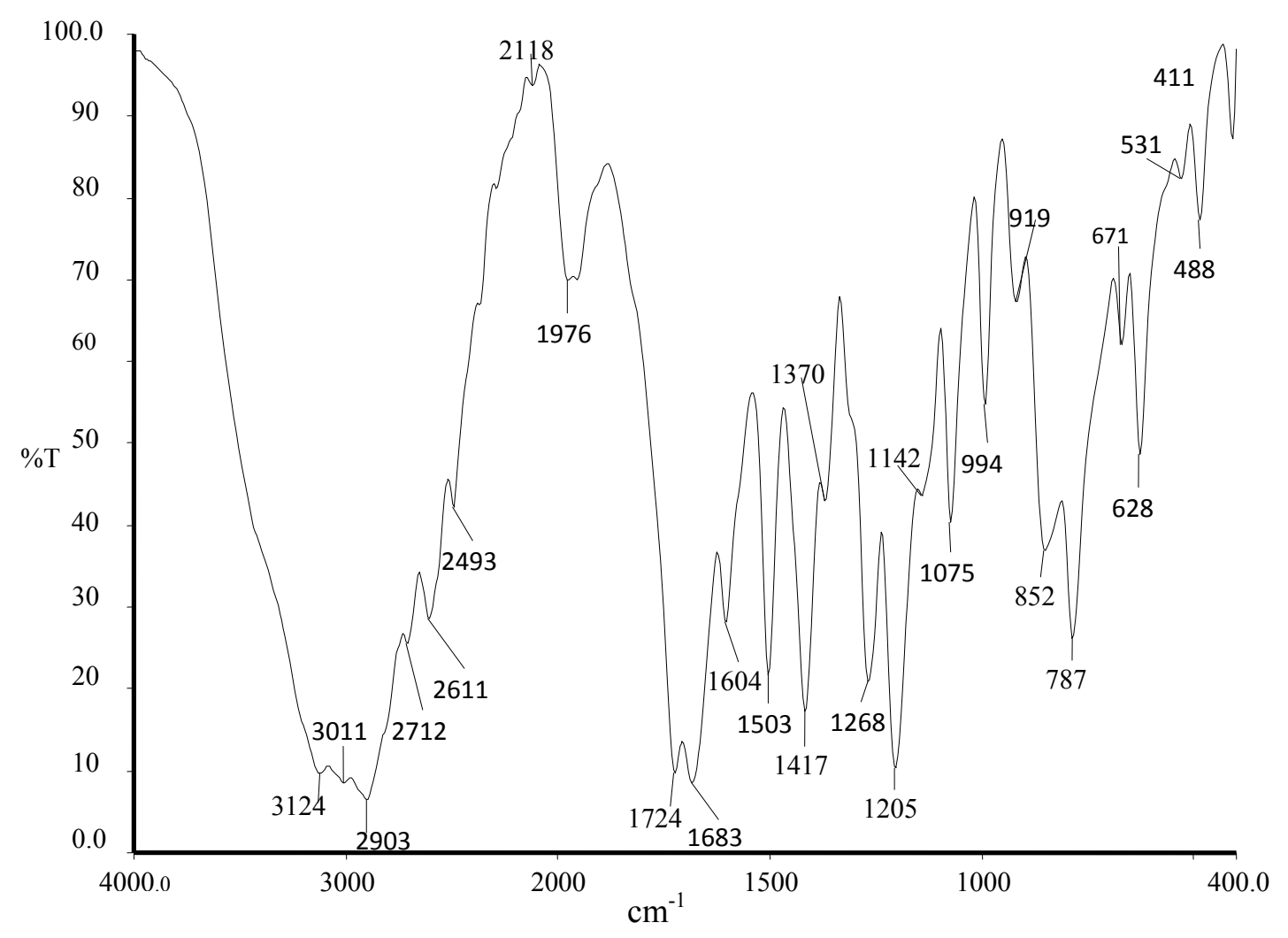

Fig. 3. FTIR spectrum of LGAHCB crystal 
Table 1. FTIR spectral band assignments of LGAHCB.

\begin{tabular}{|c|c|c|}
\hline \multicolumn{2}{|c|}{ Wave number $\left(\mathrm{cm}^{-1}\right)$} & \multirow{2}{*}{ Assignments } \\
\hline L-glutamic acid [16] & LGAHCB & \\
\hline 422 & 411 & $\mathrm{COO}^{-}$rocking \\
\hline 463 & 488 & $\mathrm{NH}_{3}{ }^{+}$torsion \\
\hline 538 & 531 & $\mathrm{COO}^{-}$wagging \\
\hline 705 & 671 & $\mathrm{COO}^{-}$in-plane-deformation \\
\hline 812 & 787 & O-H in-plane-deformation \\
\hline 871 & 852 & C-C stretching \\
\hline 951 & 994 & $\mathrm{CH}_{2}$ rocking \\
\hline 1082 & 1075 & $\mathrm{NH}_{3}{ }^{+}$rocking \\
\hline 1220 & 1205 & $\mathrm{C}-\mathrm{COO}^{-}$stretching \\
\hline 1265 & 1268 & $\mathrm{CH}_{2}$ twisting \\
\hline 1361 & 1370 & C-C-H in-plane-deformation \\
\hline 1417 & 1417 & O-H-in-plane deformation \\
\hline 1525 & 1503 & $\mathrm{NH}_{3}{ }^{+}$symmetric deformation \\
\hline 1625 & 1604 & $\mathrm{COO}^{-}$asymmetric stretching \\
\hline 1675 & 1683 & $\mathrm{C}=\mathrm{O}$ stretching \\
\hline & 1724 & $\mathrm{COO}^{-}$stretching \\
\hline 2081 & 2118 & $\mathrm{NH}_{3}{ }^{+}$degenerative deformation \\
\hline 2940 & 2906 & $\mathrm{CH}_{2}$ symmetric stretching \\
\hline 3150 & 3124 & N-H stretching \\
\hline
\end{tabular}

\subsection{Optical Studies}

The UV-Vis analysis has been measured using VARIAN CARY 5E spectrophotometer in the wavelength range of 200-1400 nm as shown in Fig.4. The absorbance is not registered until the wavelength $228 \mathrm{~nm}$ is reached from $1400 \mathrm{~nm}$. At $228 \mathrm{~nm}$, a sharp fall of transmittance to zero was observed indicating a single transition in the near UV region of LGAHCB. The material is found to be transparent to all radiations in the wavelength range of 228-1400 nm. As there is no change in the transmittance in the entire visible region, it is an advantage as it is the key requirement for materials having NLO properties. 


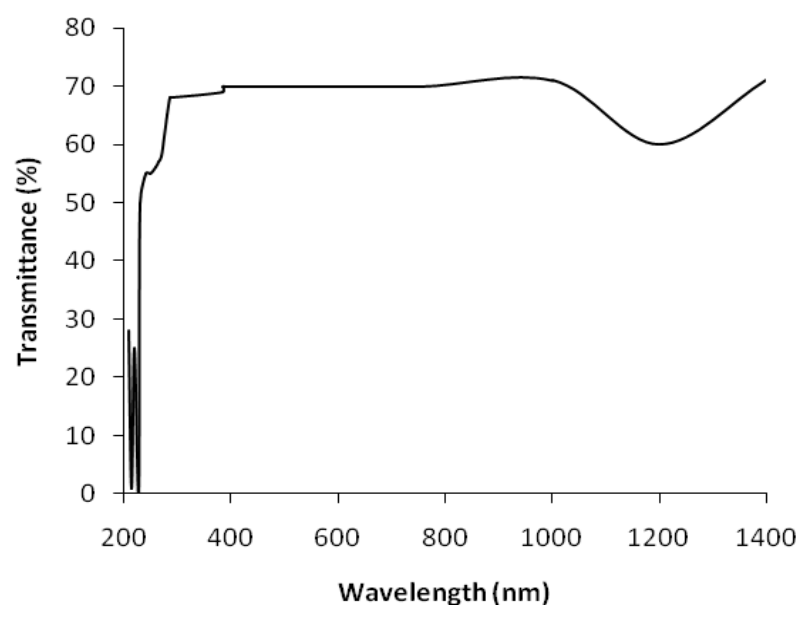

Fig. 4. Optical spectrum of LGAHCB crystal

\subsection{Microhardness Studies}

Hardness of a material is a measure of the resistance it offers to local deformation [18]. The polished faces of the as grown single crystals are subjected to Vicker's microhardness studies in order to know the mechanical behavior. Selected smooth surface of the grown crystals were subjected to Vicker's static indentation test at room temperature using Leitz Weitzlar hardness tester fitted with diamond indenter. The applied loads were varied from 5 to $45 \mathrm{~g}$. The indentation time was kept constant at 10s for each applied load and the hardness was calculated using the relation $\mathrm{H}_{\mathrm{v}}=1.85^{*} \mathrm{P} / \mathrm{d}^{2} \mathrm{~kg} / \mathrm{mm}^{2}$ where $\mathrm{P}$ is the applied load in $\mathrm{kg}$ and $\mathrm{d}$ is the diagonal length of the indentation impression in micrometer and 1.85 is a constant of a geometrical factor for the diamond pyramid. Several trials of indentation were made on the grown crystal and the average value of the diagonal length of the indentation marks at each load was taken. The Vicker's hardness of L-glutamic acid hydro chloro bromide single crystals as a function of load is depicted in Fig.5. From the graph it is found that the hardness value decreases with the increase of load upto $45 \mathrm{gm}$, above which cracks are developed. The cracks are developed when the load are increased above $45 \mathrm{gm}$ around the indentation mark as observed, which may due to the release of internal stress generated locally by indentation.

\subsection{Second Harmonic Generation}

The second harmonic generation (SHG) test on the LGAHCB crystal was performed by Kurtz powder SHG method [19]. The powdered sample of LGAHCB crystal was illuminated using the fundamental beam of 1064nm from Q-switched Nd:YAG laser. Pulse energy $4 \mathrm{~mJ} /$ pulse and pulse width of $8 \mathrm{~ns}$ and repetition rate of $10 \mathrm{~Hz}$ were used. The second harmonic signal generated in the crystalline sample was confirmed from the emission of green radiation of wavelength 
$532 \mathrm{~nm}$ collected a monochromator after separating the $1064 \mathrm{~nm}$ pump beam with an IR-blocking filter. A photo multiplier tube as used as detector. It is observed that the measured SHG efficiency of LGAHCB crystal was 1.5 times that of potassium dihydrogen phosphate (KDP).

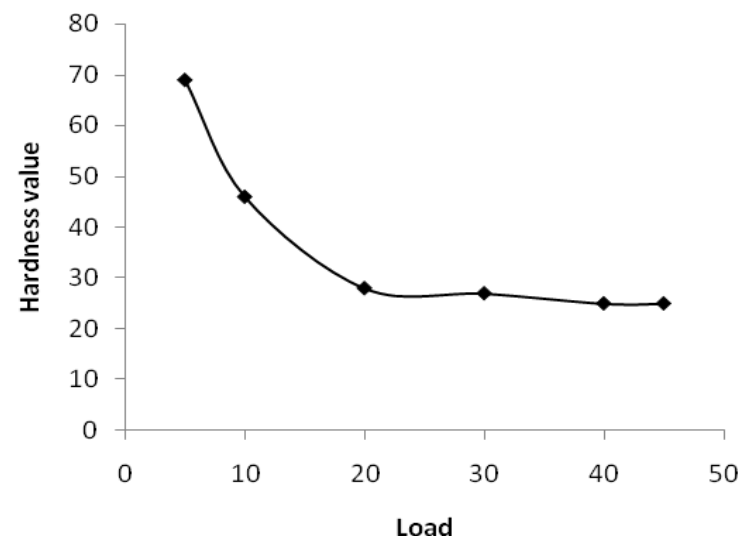

Fig. 5. Load vs Hardness number of LGAHCB crystal

\section{CONCLUSIONS}

Good optical quality of L-glutamic acid hydro chloro bromide (LGAHCB) single crystals was grown by slow evaporation solution growth technique at room temperature. From the single crystal X-ray diffraction analysis, the LGAHCB crystal has orthorhombic system. The unit cell parameter values were also determined. The presence of the various functional groups of LGAHCB has been confirmed by Fourier transform infrared spectroscopy analysis. From the optical studies, the total transparency in the entire visible region, LGAHCB will be used for optical applications. The powder second harmonic generation efficiency measurement shows the grown LGAHCB crystal having 1.5 times higher nonlinear optical efficiency than potassium dihydrogen phosphate (KDP).

\section{REFERENCES}

1. P.N. Prasad, D.J. Williams, Introduction to nonlinear optical effects in molecules and polymers, Wiley-Interscience, New York, 1991.

2. D.S. Chemla, J. Zyss, Nonlinear optical properties of organic molecules and crystals, vols. land 2, Academic Press, New York, 1987.

3. S.S. Gupte, A. Marcano, R.D. Pradhan, C.F. Desai, J. Melikechi, Appl. Phys.89 (2001) 4039. 
4. T. Uma Devi, N. Lawrence, R. Ramesh Babu, K. Ramamurthi, J. Cryst. Growth, 310 (2008) 116.

5. S.A. Martin Britto Dhas, S. Natarajan, Opt. Comm. 281 (2008) 457.

6. L. Misoguti, A.T. Varela, F.d. Nunes, V.S. Bagnato, F.E.A.Melo, J. Mendes Filho, S.C.Zilio, Opt. Mater. 6 (1996) 147.

7. M. Kitazawa, R. Higuchi, M. Takahashi, Appl. Phys. Lett. 64 (1994) 2477.

8. D. Eimert, S. Velsko, L. Davis, F. Wang, G. Loiaccono, G. Kennady, IEEE J. Quantum electron. 25 (1989) 179.

9. M.D. Aggarwal, J. Choi, W.S. Wang, K. Bhat, R.B. Lal, A.D. Shield, B.G. Penn, D.O. Frazier, J. Cryst. Growth 204 (1999) 179.

10. G. Ramesh Kumar, S. Gokul Raj, R.Sankar, R. Mohan, S. Pandi, R. Jayavel, J. Cryst. Growth 267 (2004) 213.

11. S. Dhanuskodi, K. Vasantha, Cryst. Res. Technol. 39 (2005) 259.

12. K.Kirubavathi, K.Selvaraju, R. Valluvan, N. Vijayan, S. Kumararaman, Spectrochim. acta A. 69 ( 2008) 1283.

13. K. Selvaraju, R. Valluvan, K. Kirubavathi, S. Kumararaman, Opt. Comm. 269 (2007) 230.

14. M. Delfino, G.M. Loiacono, J.A. Nicolosi, J. Solid State Chem. 23 (1978) 289.

15. K. Nakamoto, Infrared and Raman Spectra of Inorganic and Coordination Compounds, Wiley \& Sons, New York, 1986.

16. Jag Mohan, Organic Spectroscopy Principles and Applications, Narosa Publishing House, New Delhi, 2005.

17. R.S. Krishnan, V.N. Sankaranarayanan, K.Krishnan, J. Indian Inst. Sci. 55 (1973) 66.

18. B.W. Mott, Microindentation Hardness Testing, vol. 206, Butterworths, London, 1956.

19. S. K. Kurtz, T.T. Perry, J. Appl. Phys. 39 (1968) 3798. 